\title{
MS/MS studies for the selective detection of isomeric biogenic VOCs using a Townsend Discharge Triple Quadrupole Tandem MS and a PTR-Linear Ion Trap MS
}

\author{
M. Müller ${ }^{1}$, L. H. Mielke ${ }^{2}$, M. Breitenlechner ${ }^{1}$, S. A. McLuckey ${ }^{2}$, P. B. Shepson ${ }^{2,3,4}$, A. Wisthaler ${ }^{1}$, and A. Hansel ${ }^{1}$ \\ ${ }^{1}$ Institut für Ionenphysik, University of Innsbruck, Innsbruck, Austria \\ ${ }^{2}$ Department of Chemistry, Purdue University, West Lafayette, 47907, USA \\ ${ }^{3}$ Department of Earth and Atmospheric Sciences, Purdue University, West Lafayette, 47907, USA \\ ${ }^{4}$ Purdue Climate Change Research Center, Purdue University, West Lafayette, 47907, USA
}

Received: 17 July 2009 - Published in Atmos. Meas. Tech. Discuss.: 4 August 2009

Revised: 29 October 2009 - Accepted: 6 November 2009 - Published: 12 November 2009

\begin{abstract}
We performed MS/MS investigations of biogenic volatile organic compounds (BVOC) using a triple quadrupole tandem mass spectrometer (QqQ-MS) equipped with a Townsend Discharge ion source and a Proton Transfer Reaction Linear Ion Trap (PTR-LIT) mass spectrometer. Both instruments use $\mathrm{H}_{2} \mathrm{O}$ chemical ionization to produce protonated molecules. Here we report a study of the application of these instruments to determine methyl vinyl ketone (MVK) and methacrolein (MACR) and a series of monoterpenes ( $\alpha$-pinene, $\beta$-pinene, 3 -carene, limonene, myrcene, ocimene) and sesquiterpenes (humulene and farnesene). Both instruments achieved sub-ppb detection limits in the single MS mode and in the MS/MS mode for differentiating MVK and MACR. Collision induced dissociation (CID) of protonated monoterpenes and sesquiterpenes was studied under the relatively high-energy, single-to-few collision conditions of the QqQ-MS instrument and under the lowenergy, multiple collision conditions of the PTR-LIT. Differences and similarities in the breakdown curves obtained are discussed. In addition, we performed $\mathrm{MS}^{4}$ of protonated limonene to illustrate the analytical power of the PTR-LIT. In spite of the progress we have made, the selective on-line mass-spectrometric detection of individual monoterpenes or sesquiterpenes in complex mixtures currently does not yet seem to be possible.
\end{abstract}

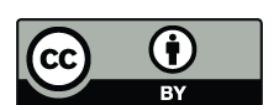

Correspondence to: A. Hansel

(armin.hansel@uibk.ac.at)

\section{Introduction}

Biogenic volatile organic compounds (BVOCs) play an important role in the production of tropospheric ozone and contribute to the formation of particulate matter, especially in continental environments (Chameides et al., 1988; Fehsenfeld et al., 1992; Meng et al., 1997; Tunved et al., 2006). While it is not surprising that BVOCs control much of the chemistry above forest environments, Biesenthal et al. (1997) found that isoprene oxidation can account for $\sim 13 \%$ of ozone production within the Vancouver, B.C. urban environment. Sotiropoulou et al. (2004) have shown that terpenes significantly impact air quality in the urban environments of Athens and Marseille. Given these observations and the very large emissions of BVOCs $(\sim 500 \mathrm{Tg} / \mathrm{Yr}$ for isoprene, $\sim 125 \mathrm{Tg} / \mathrm{Yr}$ for total terpenes, $\sim 500 \mathrm{Tg} / \mathrm{Yr}$ other BVOCs; Guenther et al., 1995) on a global scale, it is clear that a better understanding of the temporal characteristics and magnitudes of BVOC emission rates is important to the development of better ozone and particulate matter control strategies. Furthermore, it is important to note that BVOC emission influences the photooxidation capacity of the atmosphere on a local scale, due to the large contribution BVOCs can make to the total $\mathrm{OH}, \mathrm{O}_{3}$, and $\mathrm{NO}_{3}$ reactivity in the atmosphere. The longer lived BVOC photooxidation products such as ozone and secondary organic aerosol (SOA) impact the atmosphere on a more regional scale. The current status of knowledge of formation, properties and impact of SOA was recently reviewed by Hallquist et al. (2009).

Published by Copernicus Publications on behalf of the European Geosciences Union. 
These considerations result in substantial demands to improve analytical technology for in-situ BVOC measurements. BVOC concentrations are often very low, in the low ppt range, particularly for the terpenes $\left(\mathrm{C}_{10} \mathrm{H}_{16}\right)$ and sesquiterpenes $\left(\mathrm{C}_{15} \mathrm{H}_{24}\right)$ that are important SOA precursors (Saxton et al., 2007). Atmospheric BVOC measurements at low ppt levels are made within a highly complex mixture of volatile organics, $\sim 10^{9}$ times more water vapor, and $\sim 1000$ 10000 times more ozone. The situation is even more challenging than this, since many BVOCs and their oxidation products are structural isomers. Examples include methyl vinyl ketone (MVK) and methacrolein (MACR), which are produced from the oxidation of isoprene. There are more than 14 monoterpene isomers and more than 4 sesquiterpene isomers, respectively, present in the atmosphere (Fuentes et al., 2000), at widely varying concentrations. Thus, substantial separation power/selectivity is needed to quantitatively determine the individual species. This is important to achieve, since the chemistry and important reaction partners differ widely among these species (Atkinson and Arey, 1998).

The analytical requirements outlined above seem to imply two possibilities, either high resolution gas chromatography, or selective mass spectrometry. Isoprene has been measured extensively using an array of direct mass spectrometric techniques, e.g. PTR-MS (Stroud et al., 2002), CIMS (Colorado et al., 1998; Leibrock et al., 2003; Sellegri et al., 2005), and using a cylindrical ion trap (Edwards et al., 2007). For terpenes, analysis has most generally been done by capillary GC, with cartridge (Spirig et al., 2004; Kesselmeier et al., 2000) or cryogenic preconcentration (Lerdau et al., 1994). In most cases, the stationary phase was a bonded methyl silicone phase, e.g. DB-1. These chromatographic methods work well to the extent that they enable identification and determination of individual terpene species. However, they tend to be cumbersome, with marginal temporal resolution (e.g. 2-4 samples per hour).

Proton Transfer Reaction Mass Spectrometry (PTR-MS) is a powerful method for fast and sensitive determination of atmospheric VOCs (Lindinger et al., 1998). The PTR-MS technique is appealing because of its low limits of detection, and fast time response, which enables even direct VOC flux measurements (Karl et al., 2001). A PTR-TOF instrument has been recently developed combining a PTR drift tube with a high mass resolution time-of-flight MS (Müller et al., 2007). However, both conventional PTR-MS and PTR-TOFMS can only determine total terpenes (e.g. Lee et al., 2005) and cannot distinguish between different isomers. Prazeller et al. (2003) and Warneke et al. (2005a) describe the development of PTR ion trap mass spectrometers. Both approaches utilize a $3 \mathrm{D}$ ion trap as the mass analyzer, enabling collision induced dissociation (CID) based determination of isomeric VOCs. This capability was demonstrated through simultaneous determination of the isomeric compounds acetone and propanal. However, for most isomeric BVOC measurements, the instrument suffers from poor limits of detection when used in the MS/MS (MS ${ }^{2}$ ) mode. Mielke et al. (2008) have recently developed the Proton Transfer Reaction Linear Ion Trap (PTR-LIT), which utilizes a linear quadrupole ion trap mass spectrometer as the analyzer, also enabling MS/MS measurements. In principle, the PTR-LIT can achieve better limits of detection in the $\mathrm{MS}^{n}$ mode than a cylindrical ion trap because of the better trapping efficiency for injected ions. Mielke et al. (2008) demonstrated that the PTR-LIT differentiates between MVK and MACR in laboratory photochemical reaction chamber experiments.

It is still a challenge to develop selective and sensitive schemes for quantitative and fast determination of isomeric BVOCs. Here we utilize a triple quadrupole tandem mass spectrometer (QqQ-MS) and the PTR-LIT, to investigate the CID of protonated MVK and MACR, as well as of a series of protonated monoterpenes and sesquiterpenes. QqQMS based CID was conducted under relatively high-energy, single-or-few collision conditions. CID energies are welldefined and can be varied over a high energy range. However, QqQ-MS based CID is limited to MS/MS (MS ${ }^{2}$ ). The PTR-LIT sequentially deposits a low amount of energy in multiple collisions, and it can perform multiple isolation and fragmentation steps $\left(\mathrm{MS}^{n}\right)$.

In this paper, we show ion decomposition processes in the QqQ-MS as a function of ion kinetic energy. We will compare monoterpene fragmentation patterns measured by PTR-LIT and by QqQ-MS. A PTR-LIT limonene $\mathrm{MS}^{n}$ experiment is shown for a better understanding of the fragmentation process, and to demonstrate the potential of $\mathrm{MS}^{n}$ analyses. Based on our findings we will discuss the prospects for selective atmospheric PTR-LIT and QqQ-MS determination of biogenic isomeric VOCs.

\section{Experimental}

During laboratory experiments, the $\mathrm{C}_{4} \mathrm{H}_{6} \mathrm{O}$ isomers MVK and MACR, six monoterpenes $\left(\mathrm{C}_{10} \mathrm{H}_{16}\right)$, cis-ocimene, myrcene, $(-)-\alpha$-pinene, $(-)-\beta$-pinene, $(+)-3$-carene and $\mathrm{R}$ $(+)$-limonene, and two sesquiterpenes $\left(\mathrm{C}_{15} \mathrm{H}_{24}\right)$, farnesene and $\alpha$-humulene, were investigated. Chemical structures of the compounds are depicted in Fig. 1. A constant gas-phase concentration of each compound was prepared using syringe pump injection at a constant flow rate of the pure liquid compound into a flow of zero air (Liquid Calibration Unit - LCU, Ionimed Analytik GbmH, Austria). Mole fractions in the ppb-to-ppm range were stable for a time period up to several hours. In addition, calibrations of the instruments were performed using a dynamic gas calibration unit (GCU, Ionimed Analytik GbmH, Austria) and a multiple-component gas cylinder (Apel Riemer Environmental Inc., Denver, CO, USA). For the monoterpene experiments the PTR-LIT and the QqQ-MS instrument were simultaneously connected either to the LCU or to the GCU using a $60^{\circ} \mathrm{C}$ heated Teflon line. 


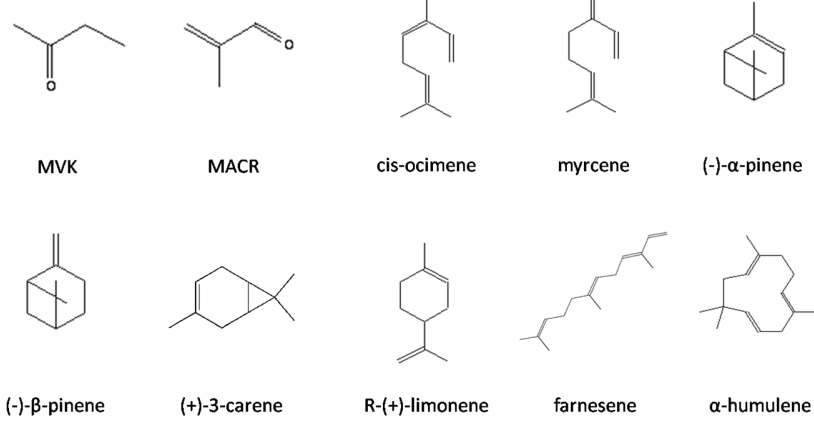

Fig. 1. Structures of MVK, MACR, the six monoterpene isomers and the two sesquiterpenes studied.

\subsection{QqQ-MS}

A modified Varian MS-320 Triple Quadrupole instrument (QqQ-MS) was used as an on-line trace gas analyzer. Protonated water and water cluster ions $\left.\mathrm{H}_{3} \mathrm{O}^{+} \cdot \mathrm{H}_{2} \mathrm{O}_{n} n=1-5\right)$ were generated in a modified Townsend discharge running with $\mathrm{H}_{2} \mathrm{O}$ as a source gas at $2 \mathrm{kV}$ discharge voltage and $8 \mathrm{hPa}$ pressure. The high proton affinity (PA) of the water clusters $(\mathrm{PA}=224.5 \mathrm{kcal} / \mathrm{mol}$ for the water trimer $n=2)$ prevents direct proton transfer reactions for most VOCs. Ionization is effected by ligand switching reactions, which deposit less energy into the product ion and lead to a very low degree of fragmentation.

$\mathrm{H}_{3} \mathrm{O}^{+} \cdot \mathrm{H}_{2} \mathrm{O}+\mathrm{VOC} \rightarrow \mathrm{VOCH}^{+} \cdot \mathrm{H}_{2} \mathrm{O}+\mathrm{H}_{2} \mathrm{O}$

$\mathrm{VOCH}^{+} \cdot \mathrm{H}_{2} \mathrm{O} \rightarrow \mathrm{VOCH}^{+}+\mathrm{H}_{2} \mathrm{O}$

Similar to PTR, ligand switching produces protonated analytes $\left(\mathrm{VOCH}^{+}\right)$in the Townsend discharge through Reactions (R1) and (R2). The results of our study suggest that the structure of the analyte molecule is not altered upon protonation. Ions, extracted from the ion source by an Einzel lens system, were collimated with a hexapole guide into the first quadrupole mass filter (Q1) and guided or dissociated in a $180^{\circ}$ curved collision cell quadrupole (CC) filled with $0.4 \times 10^{-3}-3.2 \times 10^{-3} \mathrm{hPa}$ high grade argon CID gas. Finally, ions were mass filtered with the last quadrupole mass filter (Q2) and detected with an ultra-low noise detector operated in the so-called Extended Dynamic Range (EDR) mode. All lens and quadrupole settings were automatically optimized for a set of custom compounds, interpolated and dynamically adopted for every $\mathrm{m} / \mathrm{z}$ ratio leading to an optimized ion transmission.

The QqQ-MS was operated in two different operation modes, the single quadrupole scan mode and the product ion scan mode. In the single quadrupole scan mode, only the first quadrupole (Q1) was used as a mass analyzer, and CC and $\mathrm{Q} 2$ worked as an ion guide. In the product ion scan mode, Q2 scanned for the product ions formed in the CC, when the precursor ion, selected by Q1, was fragmented by CID. Additional information on the number of collisions in $\mathrm{CC}$ is given as a Supplement (http://www.atmos-meas-tech.net/2/ 703/2009/amt-2-703-2009-supplement.pdf). The instrument software allows measurement of up to ten fragment ions with the highest signal intensities at different collision cell offset voltages $\left(\mathrm{U}_{\mathrm{CC}}\right)$, i.e. the voltage difference between $\mathrm{Q} 1$ and CC. $\mathrm{U}_{\mathrm{CC}}$ was varied between 0 and $50 \mathrm{~V}$. The selected fragment ions were measured with a dwell time of 0.1 to $10 \mathrm{~s}$. To better compare fragmentation patterns, fragment ion signals were normalized to the total ion signal. As only singlycharged ions are produced, the $m / z$ ratio is referred throughout this work as mass only, e.g. we use the notation $m / z 59$ instead of $m / z=59 \mathrm{Th}$.

\subsection{PTR-LIT}

The PTR-LIT instrument combines a PTR source (Hansel et al., 1995; Lindinger et al., 1998) with a linear ion trap (Mielke et al., 2008). The PTR part was operated in a low $E / N$ ( $E$ represents the electric field strength, $N$ the gas particle number) mode at 95 Townsend $\left(1 \mathrm{Td}=10^{-17} \mathrm{~V} \mathrm{~cm}{ }^{2}\right)$ corresponding to $400 \mathrm{~V}$ drift tube voltage. This resulted in a higher sensitivity and a lowered amount of fragmentation. The ion trap was operated at a low pressure of $1.0 \times 10^{5} \mathrm{hPa}$ by adding helium as CID gas. The injection voltage between the last drift tube lens and the quadrupole rods was set at $3 \mathrm{~V}$ to reduce dissociation upon injection into the trap. The increased sensitivity due to a lowered amount of fragmentation allowed the reduction of the fill time to $250 \mathrm{~ms}$ for most experiments. A resonant ejection voltage of $500 \mathrm{mV}$ was applied for $250 \mathrm{~ms}$ at $250 \mathrm{kHz}$ dipolar excitation frequency for monoterpenes and $200 \mathrm{kHz}$ for sesquiterpenes with no DC field applied to the rods.

Collison induced dissociation curves were recorded for each monoterpene and sesquiterpene by bringing ions into resonant excitation at $250 \mathrm{kHz}$, and $200 \mathrm{kHz}$ dipolar excitation. The dipolar excitation voltage $\left(\mathrm{U}_{\mathrm{CID}}\right.$ ) was varied from 0 to $2 \mathrm{~V}$ while monitoring the protonated molecule as well as the fragment ions. A lower mass cutoff of $m / z 20$ was observed for these experiments. For sensitivity and LOD analysis, $750 \mathrm{~ms}$ fill time was used, above which nonlinearity in the calibration curve was observed. Samples for calibration were derived from the multicomponent standard described earlier.

\section{Results}

\subsection{QqQ-MS and PTR-LIT Sensitivity and LOD}

The QqQ Townsend discharge produced a total primary ion signal (sum over all $\mathrm{H}_{3} \mathrm{O}^{+} \cdot\left(\mathrm{H}_{2} \mathrm{O}\right)_{n}$ ions) of about $10^{8}-10^{9} \mathrm{cps}$ containing low impurities of $\mathrm{O}_{2}^{+}(0.05 \%)$ and $\mathrm{NO}^{+}(1.4 \%)$. At $130^{\circ} \mathrm{C}$ ion source temperature the protonated water trimer $\left(\mathrm{H}_{2} \mathrm{O}\right)_{n} \mathrm{H}^{+}(n=3)$ was the primary ion 
Table 1. Sensitivities and LODs for selected compounds for one second integration time.

\begin{tabular}{|c|c|c|c|c|c|c|c|}
\hline \multirow[b]{3}{*}{ Compound } & \multirow[b]{3}{*}{$\mathrm{MH}^{+}[\mathrm{Th}]$} & \multicolumn{2}{|c|}{ Sensitivity } & \multirow{2}{*}{\multicolumn{2}{|c|}{$\begin{array}{l}\text { Relative Sensitivity } \\
\text { (to acetone) }\end{array}$}} & \multirow{2}{*}{\multicolumn{2}{|c|}{$\begin{array}{c}2 \sigma-\mathrm{LOD} \\
{[\mathrm{ppbv}]}\end{array}$}} \\
\hline & & QqQ-MS & PTR-LIT & & & & \\
\hline & & [cps/ppb] & [pk area/ppb] & QqQ-MS & PTR-LIT & QqQ-MS & PTR-LIT \\
\hline acetone & 59 & 84.9 & $1.20 \mathrm{E}+04$ & 1.00 & 1.00 & 0.77 & 0.59 \\
\hline MVK & 71 & N/A & $7.33 \mathrm{E}+03$ & N/A & 0.61 & 0.40 & 0.11 \\
\hline MACR & 71 & N/A & $5.60 \mathrm{E}+03$ & N/A & 0.47 & 0.60 & 0.17 \\
\hline MEK & 73 & N/A & $1.16 \mathrm{E}+04$ & N/A & 0.97 & N/A & 0.28 \\
\hline hexanone & 101 & 290.1 & N/A & 3.42 & N/A & 0.08 & N/A \\
\hline octanone & 129 & 213.6 & N/A & 2.52 & N/A & 0.14 & N/A \\
\hline benzene & 79 & 125.6 & $5.81 \mathrm{E}+03$ & 1.48 & 0.48 & 0.22 & 0.24 \\
\hline toluene & 93 & 261.5 & $1.07 \mathrm{E}+04$ & 3.08 & 0.89 & 0.12 & 0.07 \\
\hline xylene & 107 & 333.3 & $1.10 \mathrm{E}+04$ & 3.93 & 0.5 & 0.1 & 0.29 \\
\hline trichlorobenzene & 181 & 132.2 & N/A & 1.56 & N/A & 0.21 & N/A \\
\hline isoprene & 69 & 85.3 & $8.00 \mathrm{E}+03$ & 1.00 & 0.66 & 0.81 & 0.73 \\
\hline$\alpha$-pinene & 137 & 296.7 & $6.72 \mathrm{E}+03$ & 3.49 & 0.56 & 0.16 & 0.11 \\
\hline
\end{tabular}

with a relative abundance of about $60 \%$. Decreasing the ion volume temperature shifted the water cluster distribution towards higher $\mathrm{n}$. In the PTR-LIT at $95 \mathrm{Td}$, both the monomer $\left(\mathrm{H}_{2} \mathrm{O}\right) \mathrm{H}^{+}$and the dimer $\left(\mathrm{H}_{2} \mathrm{O}\right)_{2} \mathrm{H}^{+}$are present as ionizing agents.

QqQ-MS and PTR-LIT sensitivities and $2 \sigma$-LODs for three sets of selected VOCs (carbonyls, aromatics, isoprenoids) are shown in Table 1 . These data represent one second integration time for the QqQ-MS running in single quadrupole mode, and 110 averages of $1 \mathrm{~s}$ scan time for the PTR-LIT.

The QqQ-MS instrument achieved sensitivities in the 80$340 \mathrm{cps} / \mathrm{ppb}$ regime which is comparable to the performance of a conventional High Sensitivity PTR-MS instrument. A strong mass discrimination effect was observed. From an ion chemistry point of view, the sensitivities for acetone and hexanone are expected to be similar (as it is observed in PTRMS instruments) while we observed a sensitivity difference of a factor of 2.5. This can be explained by mass dependent ion discrimination caused by the auto-optimization of the QqQ-MS lens system. $2 \sigma$-LODs were in the $0.1-0.8 \mathrm{ppb}$ regime depending on the chemical background signal originating from the Townsend discharge.

The PTR-LIT sensitivity is reported as peak area per ppb in arbitrary units. The sensitivity can thus not be compared to the performance of other instruments. Relative sensitivities (normalized to acetone sensitivities) are in good agreement to what is expected from ion chemistry considerations. For MVK and MACR we expect a similar sensitivity as for acetone, but the observed relative sensitivities are somewhat low. $2 \sigma$-LODs were in the $0.1-0.7$ ppb regime. Mass discrimination effects become immediately apparent in the MS/MS mode. CID of $\alpha$-pinene at $0.15 \mathrm{~V}$ yields an $m / z, 81$ signal which is 1.5 greater than the original signal at $m / z 137$, due to the fact that fragment ion peaks are greater than the precursor peak, a greater sensitivity and a lower LOD can be obtained in the MS/MS mode.

Nevertheless, the reported $2 \sigma$-LODs of the QqQ-MS and the PTR-LIT are still a magnitude higher compared to the performance of a commercial PTR-MS (Ionicon Analytik, Austria), reaching $2 \sigma$-LODs down to 10 pptv per $\mathrm{m} / \mathrm{z}$ for one second integration time.

\subsection{Fragmentation of MVK and MACR}

Figure 2 shows the QqQ-MS breakdown curve for MVK and MACR at $2.3 \times 10^{-3} \mathrm{hPa} \mathrm{CC}$ pressure. Clear differences are visible in the relative fragmentation ratios at different CID energies, i.e. at different collision cell offset voltages. At $\mathrm{U}_{\mathrm{CC}}=17 \mathrm{~V}$, protonated $\mathrm{MVK}$ yields a high amount of the $m / z 43$ fragment ion and traces of a $m / z 41$ fragment ion, with about $65 \%$ and $10 \%$ relative signal intensities, respectively. The fragmentation pattern of protonated MACR, on the other hand, shows a maximum $m / z 43$ ion signal intensity at $\mathrm{U}_{\mathrm{CC}}=10 \mathrm{~V}$ and a maximum $m / z, 41$ signal at $\mathrm{U}_{\mathrm{CC}}=17 \mathrm{~V}$, with $45 \%$ and $35 \%$ relative signal intensities, respectively. Both protonated MVK and protonated MACR also show a small fragment at $m / z 53$ peaking at $\mathrm{U}_{\mathrm{CC}}=17 \mathrm{~V}$ and a relative increase of $m / z, 71$ and $m / z, 69$ towards higher CID voltages.

The relatively large $m / z 41$ to $m / z 43$ ratio observed for protonated MACR allows for speciated quantitation of MVK and MACR, as described for the PTR-LIT in Mielke et al. (2008). Fast on-line differentiation of MVK and MACR using the QqQ-MS will be most effective at $\mathrm{U}_{\mathrm{CC}}=10 \mathrm{~V}$ and $\mathrm{U}_{\mathrm{CC}}=17 \mathrm{~V}$. For one second integration time $2 \sigma-\mathrm{LODs}$ of the main fragment ions $m / z, 41$ and $m / z, 43$ are 35.5 ppbv and $3.1 \mathrm{ppbv}$ for MVK and $6 \mathrm{ppbv}$ and $4.5 \mathrm{ppbv}$ for MACR. Using Poisson statistics, an integration time of $1 \mathrm{~min}$ reduces 
MVK:

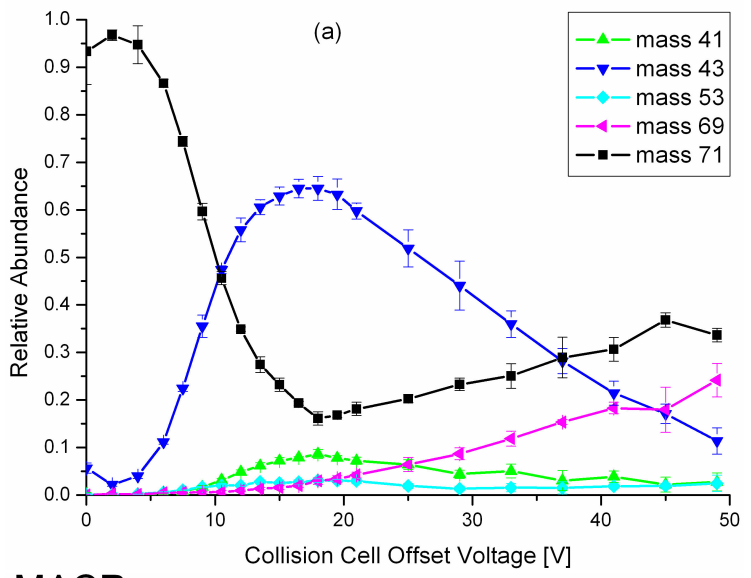

MACR:

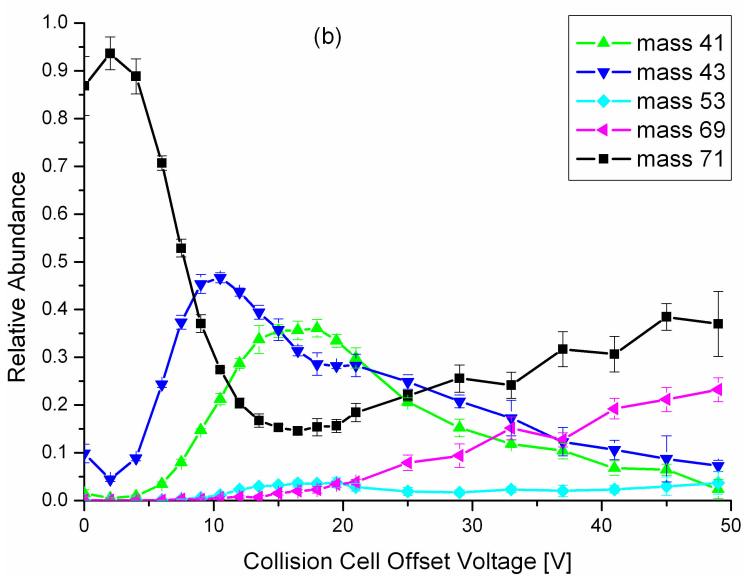

Fig. 2. Relative fragmentation patterns of MVK (a) and MACR (b) as a function of the collision cell offset voltage. Differences in $\mathrm{m} 41$ and $\mathrm{m} 43$ enable a quantitative separation.

product ion scan $2 \sigma$-LODs to $0.4 \mathrm{ppbv}$ for $m / z 43$ of MVK and $0.6 \mathrm{ppbv}$ for $m / z 43$ of MACR. The QqQ-MS is thus also able to distinguish MVK and MACR at low ppbv concentrations. As a result of the decreased ion signal intensities caused by collisions with the added CID gas, QqQ-MS LODs for MS/MS experiments are higher compared to single MS measurements.

Mielke et al. (2008) have established $2 \sigma$-LODs of $67 \mathrm{ppt}$ for differentiating MVK and MACR based on CID of $m / z 71$, with $1.2 \mathrm{~min}$ averaging times. Note that the LODs for MS/MS experiments are lower than for measurement of $m / z 71$ ions for either MVK or MACR. In PTR-LIT, MVK and MACR are differentiated on the basis of the $m / z 41$ to $\mathrm{m} / z 43$ which is 0.07 for MVK and 1.03 for MACR at $\mathrm{U}_{\mathrm{CID}}$ of 0.55 volts. Two minor fragments at $\mathrm{m} / z 53$ and $\mathrm{m} / \mathrm{z} 39$ were also detected.

\subsection{Terpene studies}

\subsubsection{MS/MS of monoterpenes}

Three selected monoterpene fragmentation patterns are plotted in Fig. 3 to compare the CID performance of the PTRLIT and the QqQ-MS instrument. One monoterpene with a bicyclic structure ( $\alpha$-pinene), one with an acyclic structure (ocimene), and one with a monocyclic structure (limonene) have been chosen for illustration. Panels A, B and C show experimental results for the QqQ-MS, and panels D, E and F for the PTR-LIT. QqQ-MS data were measured at $2.3 \times 10^{-3} \mathrm{hPa}$ CID gas pressure, operating in a multiple collision mode with up to seven collisions for $m / z$ 137. Center-of-mass collision energies for $\mathrm{U}_{\mathrm{CC}}=0-50 \mathrm{~V}$ were in the range of 0 to $11 \mathrm{eV}$. The CID fragmentation patterns of the individual monoterpenes for both the QqQ-MS and the PTR-LIT show very little difference with regard to the fragmentation products. However, fragmentation product ratios show compound specific differences. The QqQ-MS breakdown curve can be partitioned into four different energy regimes:

- i) initial fragmentation at $U_{C C}$ voltages up to $5 \mathrm{~V}$,

- ii) primary fragmentation up to $20 \mathrm{~V}$,

- iii) secondary fragmentation up to about $40 \mathrm{~V}$ and

- iv) tertiary fragmentation at higher $U_{C C}$.

In the initial fragmentation regime i) the transition between a multiple collision experiment with sequentially excited ions (comparable to the fragmentation mechanism of an ion trap) to a constant low number collision experiment occurs. Therefore, fragmentation ratios at $\mathrm{U}_{\mathrm{CC}}=0 \mathrm{~V}$ are similar to those of $\mathrm{U}_{\mathrm{CC}}=6 \mathrm{~V}$. Secondary and tertiary fragmentation is discussed in more detail in the following section.

Table 2 summarizes the fragmentation results for selected monoterpenes at 4 different CID voltages. While the differences in ion ratios are statistically significant, it will be difficult to selectively quantify individual monoterpenes in a complex mixture based only on small differences in the MS/MS spectra.

McLafferty (1993) noted that monoterpenoid hydrocarbons containing a cyclohexane ring (e.g. limonene and $\alpha$ pinene) exhibit spectra which are consistent with initial isomerization to a cyclohexene structure, plus other rearrangements, such as methyl migration. Therefore, the similar fragmentation patterns suggest isomerization due to ionization, even caused by the soft proton transfer reaction.

MS/MS of monoterpenes in the PTR-LIT produced fragment ions at $m / z$ 109, $m / z 95, m / z 81$ and $m / z 79$. For all analyzed monoterpenes $m / z 137$ rapidly decreased at a dipolar excitation voltage of $0.05 \mathrm{~V}$. As a tradeoff between total ion signal intensity and significant differences in the fragmentation patterns an optimum dipolar excitation voltage of $0.35 \mathrm{~V}$ is proposed. Table 3 summarizes the measured PTR-LIT 

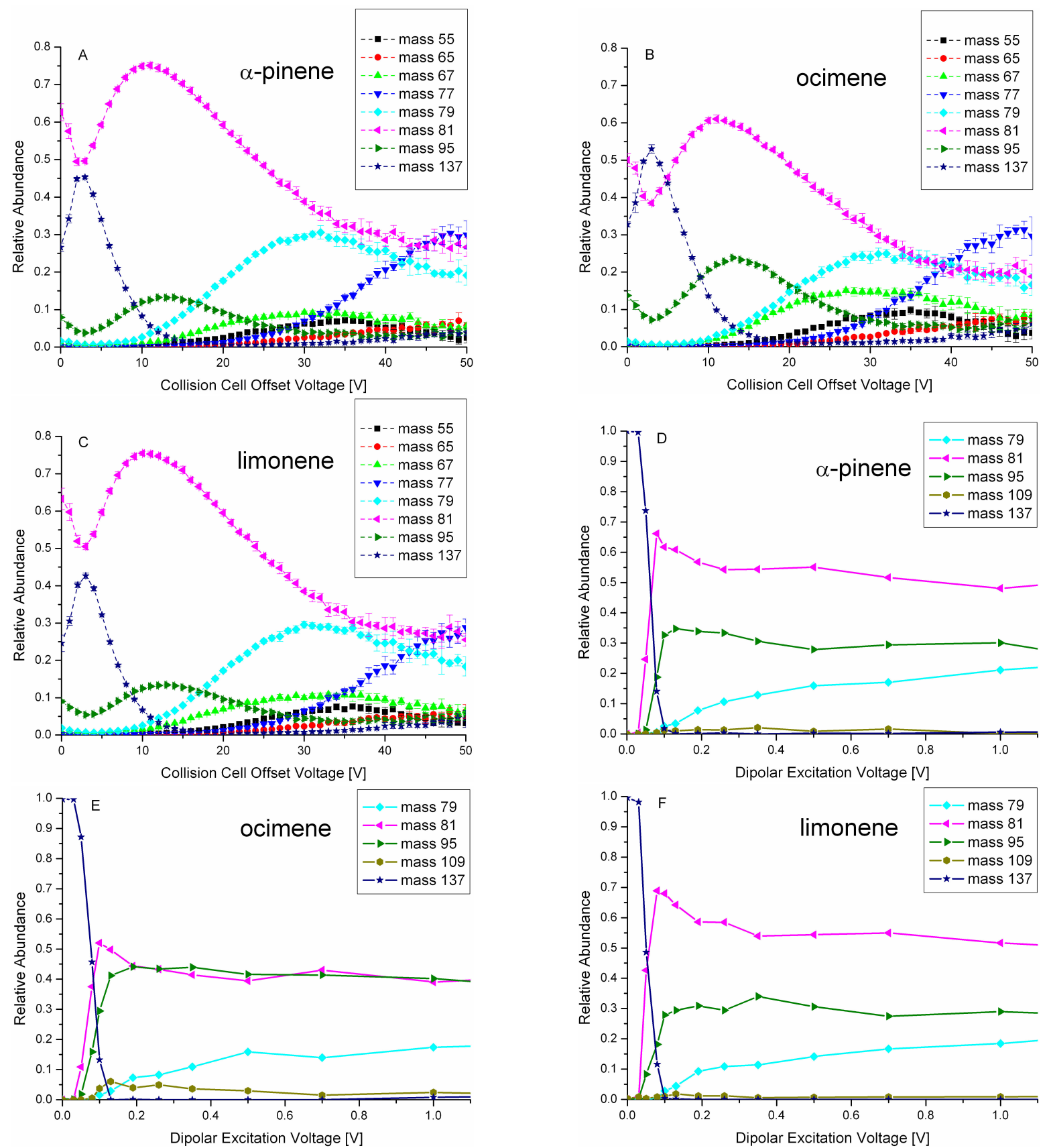

Fig. 3. The QqQ-MS relative fragmentation patterns as a function of the collision cell offset voltage for $\alpha$-pinene, ocimene and limonene are shown in panels (A), (B) and (C). Comparable PTR-LIT fragmentation patterns as a function of the dipolar excitation voltage are depicted in panels (D), (E) and (F).

fragmentation patterns at $0.35 \mathrm{~V}$ dipolar excitation voltage for selected monoterpenes. For the PTR-LIT the fragment relative signal intensities are very similar, although it might be possible to distinguish ocimene based on the $m / z 109$ to $\mathrm{m} / \mathrm{z} 81$ ratios.

Comparing the PTR-LIT fragmentation ratios to the QqQMS fragmentation ratios, differences are visible, e.g. com- paring the limonene $\mathrm{m} / \mathrm{z}, 95$ to $\mathrm{m} / \mathrm{z} 81$ ratios for the PTRLIT at $\mathrm{U}_{\mathrm{CID}}=0.35 \mathrm{~V}$ and for the QqQ-MS at $\mathrm{U}_{\mathrm{CC}}=6 \mathrm{~V}$, the ratios were 0.63 and 0.17 respectively. In addition to instrumental discrimination effects, there are significant differences in time-frames, numbers of collisions, collision energies, degrees of excitation of first generation product ions, etc., between the ion trap and triple quadrupole MS/MS 
Table 2. Relative signal intensities of the main fragment ions of the analyzed monoterpenes at four different CID voltages and corresponding fragmentation ratios $(\mathrm{m} / \mathrm{z}, 137 / \mathrm{m} / \mathrm{z} 81, \mathrm{~m} / \mathrm{z}, 5 / \mathrm{m} / \mathrm{z}, 81, \mathrm{~m} / \mathrm{z}, 79 / \mathrm{m} / \mathrm{z}, 67$ and $\mathrm{m} / \mathrm{z}, 81 / \mathrm{m} / \mathrm{z}, 77)$.

\begin{tabular}{|c|c|c|c|c|c|c|c|c|c|c|c|}
\hline \multirow{2}{*}{$\mathrm{U}_{\mathrm{CC}}[\mathrm{V}]$} & \multirow{2}{*}{$\begin{array}{c}\text { fragment ions } \\
m / z \text { [Th] }\end{array}$} & \multicolumn{2}{|c|}{$\alpha$-pinene ${ }^{1}$ and $\beta$-pinene ${ }^{1}$} & \multicolumn{2}{|c|}{ 3-carene } & \multicolumn{2}{|c|}{ limonene } & \multicolumn{2}{|c|}{ myrcene } & \multicolumn{2}{|c|}{ ocimene } \\
\hline & & signal [\%] & ratio & signal $[\%]$ & ratio & signal $[\%]$ & ratio & signal [\%] & ratio & signal [\%] & Ratio \\
\hline \multirow{2}{*}{3} & 137 & 45 & \multirow{2}{*}{0.91} & 51 & \multirow{2}{*}{1.19} & 43 & \multirow{2}{*}{0.84} & 47 & \multirow{2}{*}{1.10} & 53 & \multirow{2}{*}{1.38} \\
\hline & 81 & 50 & & 42 & & 51 & & 43 & & 38 & \\
\hline \multirow{2}{*}{11} & 95 & 13 & \multirow{2}{*}{0.17} & 20 & \multirow{2}{*}{0.31} & 13 & \multirow{2}{*}{0.17} & 23 & \multirow{2}{*}{0.38} & 22 & \multirow{2}{*}{0.36} \\
\hline & 81 & 75 & & 65 & & 75 & & 61 & & 61 & \\
\hline \multirow{2}{*}{32} & 79 & 31 & \multirow{2}{*}{3.53} & 25 & \multirow{2}{*}{1.77} & 29 & \multirow{2}{*}{2.79} & 24 & \multirow{2}{*}{1.56} & 25 & \multirow{2}{*}{1.77} \\
\hline & 67 & 9 & & 14 & & 10 & & 15 & & 14 & \\
\hline \multirow{2}{*}{50} & 81 & 27 & \multirow{2}{*}{0.89} & 20 & \multirow{2}{*}{0.62} & 26 & \multirow{2}{*}{0.89} & 21 & \multirow{2}{*}{0.67} & 19 & \multirow{2}{*}{0.63} \\
\hline & 77 & 30 & & 33 & & 29 & & 32 & & 30 & \\
\hline
\end{tabular}

1 identical fragmentation patterns were observed

Table 3. PTR-LIT relative contribution of the primary fragments at $\mathrm{U}_{\mathrm{CID}}=0.35 \mathrm{~V}$, ratio of $\mathrm{m} / \mathrm{z}, 95$ and $\mathrm{m} / \mathrm{z}, 81$ signal and the relative ion intensity.

\begin{tabular}{lcccccc}
\hline $\mathrm{U}_{\mathrm{CID}}=0.35 \mathrm{~V}$ & $\alpha$-pinene & $\beta$-pinene & 3-carene & limonene & myrcene & ocimene \\
\hline$m / z[\mathrm{Th}]$ & 13 & 14 & 14 & 11 & 12 & 11 \\
\hline 79 & 54 & 54 & 53 & 54 & 50 & 41 \\
81 & 31 & 31 & 32 & 34 & 37 & 44 \\
95 & 2 & 1 & 1 & 1 & 1 & 4 \\
109 & 0.56 & 0.58 & 0.61 & 0.63 & 0.73 & 1.06 \\
$\mathrm{~m} \mathrm{95/m} \mathrm{81}$ & & & relative signal [\%] \\
\hline
\end{tabular}

experiments. Differences in product ion ratios, for this reason, are hardly surprising. Any of these differences, or a combination thereof, can give rise to differences of the magnitude noted here.

To demonstrate the $\mathrm{MS}^{n}$ capabilities of the PTR-LIT, and to elucidate the breakdown pattern for comparison with the QqQ-MS, an $\mathrm{MS}^{4}$ experiment for limonene is shown in Fig. 4. Panel (a) shows a PTR-LIT spectrum (fill and scanout) after $0.25 \mathrm{~s}$ fill time of limonene. Similar to a PTR-MS, limonene signals at $\mathrm{m} / \mathrm{z} 81, \mathrm{~m} / \mathrm{z} 95$ and $\mathrm{m} / \mathrm{z} 137$ are visible as a result of fragmentation in the drift tube with $m / z, 32$ and $m / z, 37$ representing $\mathrm{O}_{2}^{+}$and $\left(\mathrm{H}_{2} \mathrm{O}\right)_{2} \mathrm{H}^{+}$respectively (note the very low level of trimer at $\mathrm{m} / \mathrm{z} 55$ ). Panel (b) shows the isolation ability for $m / z 137$, protonated limonene. Isolation with very little loss of signal is possible. Panel (c) illustrates CID of $m / z$, 137 with $1 \mathrm{~V}$ dipolar excitation voltage (second order MS spectrum, $\mathrm{MS}^{2}$ ) fragmenting to $m / z 81$ and $m / z 95$. The sum of the resulting ion signals of $m / z 81$ and $\mathrm{m} / z 95$ is about a factor of 3 higher than the precursor ion at $m / z, 137$ suggesting a decreasing extraction and detection efficiency towards higher $\mathrm{m} / \mathrm{z}$. Dissociation of the isolated $\mathrm{m} / z 95$ ion is shown in panel (d) $\left(\mathrm{MS}^{3}\right)$, yielding fragmentation products at $m / z 67$ and $m / z 93$. Again, $m / z 67$ was iso- lated and dissociated yielding fragments at $m / z 41$ and $m / z 39$ $\left(\mathrm{MS}^{4}\right.$, panel (e)). Further fragmentation of either $m / z 41$ or $\mathrm{m} / \mathrm{z} 39$ did not yield fragments above the low mass cut-off of $m / z 20$. MS ${ }^{3}$ fragmentation of $m / z 81$ is depicted in panel (f) resulting in $\mathrm{m} / z 79$ and $\mathrm{m} / \mathrm{z} 55$. Further fragmentation of $\mathrm{m} / \mathrm{z} 55$ does not show new fragmentation products above the low mass cut-off (data not shown). The PTR-LIT capability to perform multiple MS experiments by sequential isolation and dissociation of ions $\left(\mathrm{MS}^{n}\right.$ ) enables a detailed analysis of the fragmentation pathway. Figure 5 demonstrates the fragmentation pathway for limonene obtained with the PTR-LIT including the loss of neutral products.

These results allow us to better interpret the results obtained in the QqQ-MS based CID. The products observed at high $\mathrm{U}_{\mathrm{CC}}$ voltages correspond to products obtained via sequential CID in the PTR-LIT. From panel $C$ in Figures 4 and 5 we deduce that $m / z 55$ and $m / z, 79$ are secondary fragment ions arising from the $m / z 81$ ion, and $m / z 67$ is a secondary fragment ion arising from the $m / z 95$ ion. 

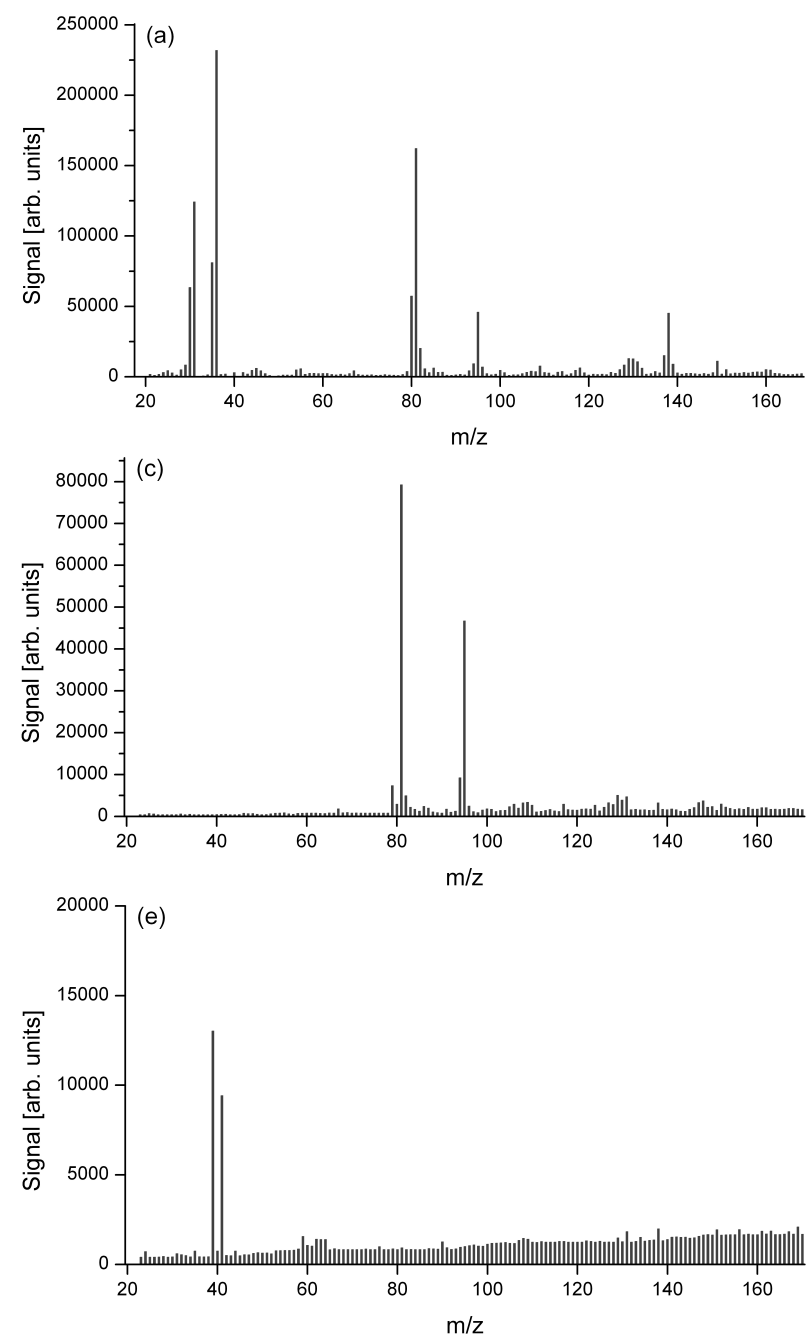
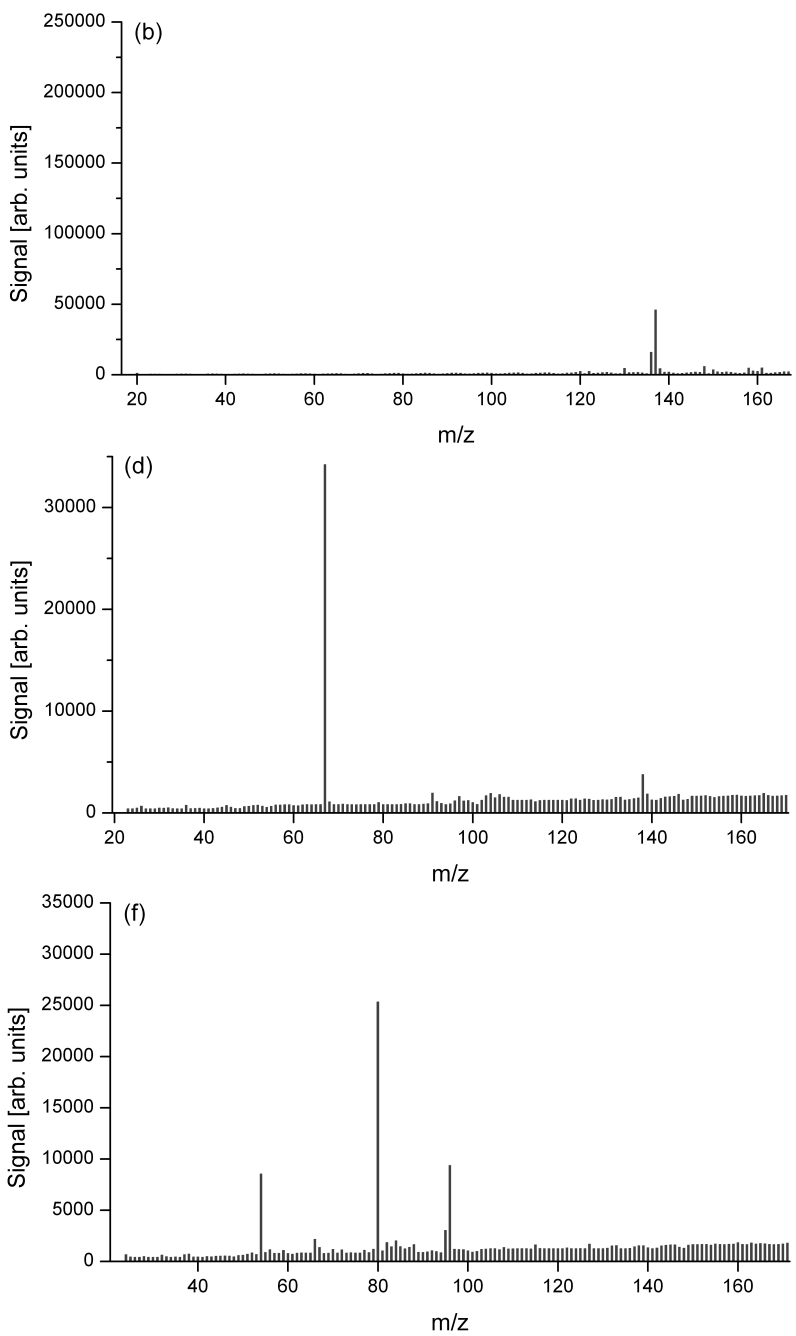

Fig. 4. Panel (a) shows a PTR-LIT (fill and scanout) spectrum after $0.25 \mathrm{~s}$ fill time for limonene. Panel (b) shows the isolation ability for $\mathrm{m} / \mathrm{z}$ 137. Panel (c) illustrates the CID spectrum for $\mathrm{m} / \mathrm{z} 137$ with $1 \mathrm{~V}$ dipolar excitation voltage. Panel (d) illustrates the CID spectrum for the isolated $\mathrm{m} / \mathrm{z}, 95$ product, and panel (e) the further CID spectrum for the isolated $\mathrm{m} / \mathrm{z} 67$ product. Panel (f) depicts the CID spectrum for $m / z 81$.

\subsubsection{Sesquiterpenes}

The relative abundances of the ten most prominent fragment ions derived from the protonated forms of farnesene and humulene are shown in Table 4. The differences in fragment ion abundances were only minor, even if an acyclic sesquiterpene was compared to a monocyclic species. For the QqQ-MS, the most significant differences in relative signal intensities were found in the $\mathrm{m} / z 149$ to $\mathrm{m} / z 121$ ratio at $\mathrm{U}_{\mathrm{CC}}=12 \mathrm{~V}$ and in the $m / z 93$ to $m / z 81$ ratio at $\mathrm{U}_{\mathrm{CC}}=33 \mathrm{~V}$. The PTR-LIT produced the same 10 most abundant fragment ions. For the PTR-LIT, a $\mathrm{U}_{\mathrm{CID}}=0.13 \mathrm{~V}$ was used. Maximum absolute signal intensities were obtained at this value and ratios of the most abundant fragments did not change as a function of the dipolar excitation voltages. For both instruments the data obtained suggest that a simple mixture of farnesene and humulene in a simple binary mixture could be quantitatively determined using the $m / z, 149$ to $m / z, 121$ ratio and the $m / z 93$ to $m / z, 81$ ratio. The analysis of a complex mixture of sesquiterpenes is, however, complicated by the similarity in the fragmentation patterns of different sesquiterpenes.

\section{Conclusions}

It has been demonstrated that the QqQ-MS instrument equipped with a Townsend Discharge $\mathrm{H}_{2} \mathrm{O}$ chemical ionization source produces similar VOC product ion spectra as a conventional PTR-MS instrument. This offers the possibility to use this instrument for structural elucidation of isomeric ions. The instrument performance was compared to that of a PTR-LIT. Single MS $2 \sigma$-LODs were in the 0.1 to $0.8 \mathrm{ppb}$ range for both instruments. MS/MS $2 \sigma$-LODs 
Table 4. Highest fragment ion signals for humulene and farnesene at $\mathrm{U}_{\mathrm{CC}}=12 \mathrm{~V}$ and $33 \mathrm{~V}$ and corresponding fragmentation ratios of $\mathrm{m} / \mathrm{z}, 149 / \mathrm{m} / \mathrm{z}, 121$ and $\mathrm{m} / \mathrm{z}, 93 / \mathrm{m} / \mathrm{z} 81$.

\begin{tabular}{|c|c|c|c|c|c|c|c|c|c|c|c|c|c|}
\hline \multirow{2}{*}{$\begin{array}{l}\text { QqQ-MS } \\
\text { compound }\end{array}$} & \multicolumn{11}{|c|}{ relative abundance [\%] } & \multirow{2}{*}{$\begin{array}{c}m / z 149 / \\
m / z 121\end{array}$} & \multirow{2}{*}{$\begin{array}{c}m / z 93 / \\
m / z 81\end{array}$} \\
\hline & $\mathrm{U}_{\mathrm{CC}}[\mathrm{V}]$ & $m / z 81$ & $m / z 93$ & $m / z 95$ & $m / z 107$ & $m / z 109$ & $m / z 121$ & $m / z 123$ & $m / z, 135$ & $m / z 149$ & $m / z 205$ & & \\
\hline humulene & 12 & 8 & 5.1 & 15.5 & 6 & 12.6 & 10.5 & 11.5 & 8.3 & 17.6 & 3.3 & 1.7 & 0.6 \\
\hline farnesene & 12 & 11.3 & 5.5 & 14.5 & 5.8 & 13.6 & 20.4 & 5.3 & 8.5 & 11.4 & 3.3 & 0.6 & 0.5 \\
\hline humulene & 33 & 33.2 & 17.8 & 10.6 & 8.1 & 3.8 & 3.5 & 1.5 & 1.2 & 1.1 & 0.2 & 0.3 & 0.5 \\
\hline farnesene & 33 & 20.1 & 27.6 & 9.3 & 8.2 & 3.8 & 8.3 & 0.4 & 0.3 & 1.4 & 0.3 & 0.2 & 1.4 \\
\hline PTR-LIT & \multicolumn{11}{|c|}{ relative abundance $[\%]$} & $m / z 149 /$ & $m / z 93 /$ \\
\hline compound & $\mathrm{U}_{\mathrm{CID}}[\mathrm{V}]$ & $m / z 81$ & $m / z 93$ & $m / z 95$ & $m / z 107$ & $m / z 109$ & $m / z 121$ & $m / z 123$ & $m / z 135$ & $m / z 149$ & $m / z 205$ & $m / z 121$ & $m / z 81$ \\
\hline humulene & 0.13 & 2.8 & 0.4 & 16.0 & 2.0 & 14.5 & 5.5 & 7.3 & 14.2 & 34.9 & 2.5 & 6.3 & 0.1 \\
\hline farnesene & 0.13 & 6.3 & 2.5 & 15.7 & 1.9 & 15.8 & 14.7 & 7.0 & 12.6 & 22.7 & 0.8 & 1.6 & 0.4 \\
\hline
\end{tabular}

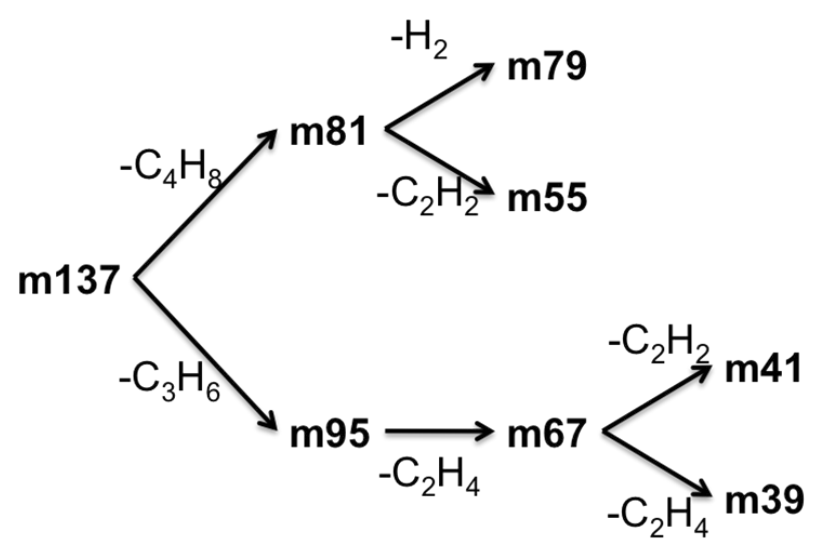

Fig. 5. Fragmentation pathway of limonene obtained by a $\mathrm{MS}^{n}$ PTR-LIT CID experiment.

for MVK and MACR were $0.4 \mathrm{ppbv}$ and $0.6 \mathrm{ppbv}$, respectively, for the QqQ-MS instrument and $0.11 \mathrm{ppbv}$ and 0.17 , respectively, for PTR-LIT - all of which are suitable for ambient air measurements in some environments. Fragmentation patterns of six monoterpenes ( $\alpha$-pinene, $\beta$-pinene, 3 carene, limonene, myrcene, ocimene) were obtained for both instruments. The double-ring monoterpene $\alpha$-pinene showed a different fragmentation pattern than the linear monoterpene ocimene. No differences were found in structurally similar monoterpenes such as $\alpha$-pinene and $\beta$-pinene. The similarities in the fragmentation patterns of structurally similar monoterpenes complicate selective detection of individual monoterpenes in complex mixtures. The $\mathrm{MS}^{n}$ ability of the PTR-LIT may be useful to overcome this problem - in addition to revealing sequential dissociation pathways, which cannot be observed in the QqQ-MS instrument. The sesquiterpenes humulene and farnescene could be differentiated by both QqQ-MS and PTR-LIT using the $m / z, 149$ to $m / z, 121$ or $m / z 93$ to $m / z, 81$ ratio. We anticipate that selective detection of individual sesquiterpenes in complex mixtures to be problematic. Further work with the QqQ-MS will focus on the reduction of chemical background and the improvement of the long-term signal stability of the ion source. Furthermore, we will explore the potential of ion neutral reactions in the ion trap of the PTR-LIT instrument for differentiating mixtures of monoterpenes, sesquiterpenes, or other isomeric compounds of interest.

Acknowledgements. The PTR-LIT work was supported by the US National Science Foundation under Grant CHE-0314349. The QqQ-MS was funded via the "Uni Infrastruktur III" program. Work on the QqQ-MS was funded by the Österreichische Forschungsförderungsgesellchaft $\mathrm{mbH}$ - Basisprogramme. Further support was provided by Ionimed Analytik $\mathrm{GmbH}$, Innsbruck, Austria. We acknowledge the initial QqQ-MS work performed by Pawel Cias.

Edited by: H. Schlager

\section{References}

Atkinson, R. and Arey, J.: Atmospheric chemistry of biogenic organic compounds, Acc. Chem. Res., 31, 574-583, 1998.

Chameides, W. L., Lindsay, R. W., Richardson, J., and Kiang, C. S.: The Role Of Biogenic Hydrocarbons In Urban Photochemical Smog - Atlanta As A Case-Study, Science, 241, 1473-1475, 1988.

Colorado, A., Barket, D. J., Hurst, J. M., and Shepson, P. B.: A FastResponse Method for Determination of Atmospheric Isoprene Using Quadrupole Ion Trap Mass Spectrometry, Anal. Chem., 70, 5129-5135, 1998.

de Gouw, J. and Warneke, C.: Measurements of volatile organic compounds in the earths atmosphere using proton-transferreaction mass spectrometry, Mass Spectrom. Rev., 26, 223-257, 2007.

Edwards, G. D., Shepson, P. B., Grossenbacher, J. W., Wells, J. M., Patterson, G. E., Barket, D. J., Pressley, S., Karl, T., and Apel, E.: Development of an Automated Cylindrical Ion Trap Mass Spectrometer for Determination of Atmospheric Volatile Organic Compounds, Anal. Chem., 79, 5040-5050, 2007.

Fehsenfeld, F., Calvert, J., Fall, R., Goldan, P., Guenther, A. B., Hewitt, N. C., Lamb, B., Liu, S., Trainer, M., Westberg, H., 
and Zimmerman, P.: Emissions of volatile organic compounds from vegetation and the implications for atmospheric chemistry, Global Biogeochem. Cy., 6, 389-430, 1992.

Fuentes, J. D., Lerdau, M., Atkinson, R., Baldocchi, D., Bottenheim, J. W., Ciccioli, P., Lamb, B., Geron, C., Gu, L., Guenther, A., Sharkey, T. D., and Stockwell, W.: Biogenic hydrocarbons in the atmospheric boundary layer: A review, Bull. Am. Meteor. Soc., 81, 1537-1575, 2000.

Hallquist, M., Wenger, J. C., Baltensperger, U., Rudich, Y., Simpson, D., Claeys, M., Dommen, J., Donahue, N. M., George, C., Goldstein, A. H., Hamilton, J. F., Herrmann, H., Hoffmann, T., Iinuma, Y., Jang, M., Jenkin, M. E., Jimenez, J. L., Kiendler-Scharr, A., Maenhaut, W., McFiggans, G., Mentel, Th. F., Monod, A., Prèvòt, A. S. H., Seinfeld, J. H., Surratt, J. D., Szmigielski, R., and Wildt, J.: The formation, properties and impact of secondary organic aerosol: current and emerging issues, Atmos. Chem. Phys., 9, 5155-5235, 2009, http://www.atmos-chem-phys.net/9/5155/2009/.

Karl, T., Guenther, A., Jordan, A., Fall, R., and Lindinger, W.: Eddy covariance measurement of biogenic oxygenated VOC emissions from hay harvesting, Atmos. Environ., 35, 491-495, 2001.

Kesselmeier, J., Kuhn, U., Wolf, A., Andreae, M. O., Ciccioli, P., Brancaleoni, E., Frattoni, M., Guenther, A., Greenberg, J., Vasconcellos, P. D., de Oliva, T., Tavares, T., and Artaxo, P.: Atmospheric volatile organic compounds (VOC) at a remote tropical forest site in central Amazonia, Atmos. Environ., 34, 4063-4072, 2000.

Lee, A., Schade, G. W., Holzinger, R., and Goldstein, A. H.: A comparison of new measurements of total monoterpene flux with improved measurements of speciated monoterpene flux, Atmos. Chem. Phys., 5, 505-513, 2005, http://www.atmos-chem-phys.net/5/505/2005/.

Leibrock, E., Huey, L. G., Goldan, P. D., Kuster, W. C., Williams, E., and Fehsenfeld, F. C.: Ground-based intercomparison of two isoprene measurement techniques, Atmos. Chem. Phys., 3, 6772, 2003, http://www.atmos-chem-phys.net/3/67/2003/.

Lerdau, M., Dilts, S. B., Westberg, H., Lamb, B. K., and Allwine, E. J.: Monoterpene Emission From Ponderosa Pine, J. Geophys. Res., 99, 16609-16615, 1994.

Lindinger, W., Hansel, A., and Jordan, A.: Proton-transfer-reaction mass spectrometry (PTR-MS): on-line monitoring of volatile organic compounds at pptv levels, Chem. Soc. Rev., 27, 347-354, 1998.

McLafferty, F. W. and Tureček, F.: Interpretation of Mass Spectra, Fourth Edition, University Science Books, Sausalito, CA, 1993.

Meng, Z., Dabdub, D., and Seinfeld, J. H.: Chemical coupling between atmospheric ozone and particulate matter, Science, 277, 116-119, 1997.

Mielke, L. H., Erickson, D. E., McLuckey, S. A., Müller, M., Wisthaler, A., Hansel, A., and Shepson, P. B. : Development of a Proton-Transfer-Reaction Linear Ion Trap Mass Spectrometer for Quantitative Determination of Volatile Organic Compounds, Anal. Chem., 80(21), 8171-8177, 2008.
Müller, M., Graus, M., Wisthaler, A., and Hansel, A.: Performance Assessment of a Recently Developed High Resolution PTRTOFMS Instrument, Third International Conference on PTR MS and its application, edited by: Hansel, A. and Märk, T., Innsbruck University Press (IUP), Innsbruck, 2007.

Prazeller, P., Palmer, P. T., Boscaini, E., Jobson, T., and Alexander, M.: Proton Transfer Reation Ion Trap Mass Spectrometer, Rapid Commun. Mass Sp., 17, 1593-1599, 2003.

Saxton, J. E., Lewis, A. C., Kettlewell, J. H., Ozel, M. Z., Gogus, F., Boni, Y., Korogone, S. O. U., and Serça, D.: Isoprene and monoterpene measurements in a secondary forest in northern Benin, Atmos. Chem. Phys., 7, 4095-4106, 2007, http://www.atmos-chem-phys.net/7/4095/2007/.

Sellegri, K., Umann, B., Hanke, M., and Arnold, F.: Deployment of a ground-based CIMS apparatus for the detection of organic gases in the boreal forest during the QUEST campaign, Atmos. Chem. Phys., 5, 357-372, 2005, http://www.atmos-chem-phys.net/5/357/2005/.

Spirig, C., Guenther, A., Greenberg, J. P., Calanca, P., and Tarvainen, V.: Tethered balloon measurements of biogenic volatile organic compounds at a Boreal forest site, Atmos. Chem. Phys., 4, 215-229, 2004, http://www.atmos-chem-phys.net/4/215/2004/.

Steeghs, M. M. L., Crespo, E., and Harren, F. J. M.: Collision induced dissociation study of 10 monoterpenes for identification in trace gas measurements using the newly developed protontransfer reaction ion trap mass spectrometer, Int. J. Mass Spectrom., 263, 204-212, 2007.

Stroud, C., A., Roberts, J. M., Williams, E. J., Hereid, D., Angevine, W. M., Fehsenfeld, F. C., Wisthaler, A., Hansel, A., MartinezHarder, M., Harder, H., Brune, W. H., Hoenninger, G., Stutz, J., and White, A. B.: Nighttime isoprene trends at an urban forested site during the 1999 Southern Oxidant Study, J. Geophys. Res., 107, 4291, doi:10.1029/2001JD000959, 2002.

Tunved, P., Hansson, H. C., Kerminen, V. M., Ström, J., Dal Maso, M., Lihavainen, H., Viisanen, Y., Aalto, P. P., Komppula, M., and Kulmala, M.: High Natural Aerosol Loading over Boreal Forests, Science, 312, 261-263, 2006.

Warneke, C., de Gouw, J. A., Lovejoy, E. R., and Murphy, P.C.: Development of Proton-Transfer Ion Trap-Mass Spectronetry: Online Detection and Identification of Volatile Organic Compounds in Air, J. Am. Soc. Mass Spectrom., 16, 1316-1324, 2005a.

Warneke, C., Kato, S., de Gouw, J. A., Goldan, P. D., Kuster, W. C., Shao, M., Lovejoy, E. R., Fall, R., and Fehsenfeld, F.C.: Online Volatile Organic Compound Measurements Using a Newly Developed Proton-Transfer Ion-Trap Mass Spectrometry Instrument During New England Air Quality Study - Intercontinental Transport and Chemical Transformation 2004, Performance, Intercomparison, and Compound Identification, Environ. Sci. Technol., 39, 5390-5397, 2005b. 